\title{
Orthostatic Intolerance and Autonomic Dysfunction following Bariatric Surgery: A retrospective study and review of the literature.
}

Vanessa Ponnusamy ${ }^{1}$, Andrew P. Owens ${ }^{1,2}$, Sanjay Purkayastha ${ }^{3}$, Valeria Iodice ${ }^{1}$, Christopher J. Mathias 1,2, 4,5

1. Autonomic Unit, National Hospital for Neurology and Neurosurgery, University College London Hospitals, UK

2. Institute of Neurology, University College London, UK

3. Bariatric Surgery, Imperial College NHS Healthcare Trust, UK

4. The Lindo Wing, Imperial College NHS Healthcare Trust, UK

4. Hospital of St John \& St Elizabeth, London, UK

Corresponding Author:

Vanessa Ponnusamy

Autonomic Unit

National Hospital for Neurology and Neurosurgery

Queen Square

London WC1N 3BG

Corresponding Author's telephone: 02034483413

Corresponding Author's Fax: 02034481722

Corresponding Author's Email: Vanessa.Ponnusamy@uclh.nhs.uk

Number of words in abstract: 180

Number of words in main text: 2744

Number of figures: 1

Number of tables: 3

Conflict of interest: None. 


\begin{abstract}
The prevalence and costs of the obesity epidemic and obesity-related conditions, including diabetes mellitus, is consistently increasing worldwide. Bariatric medicine is attempting to address this with weight loss and exercise programmes, and with increasing frequency, various forms of bariatric surgery. There has been considerable success reported after bariatric surgery but not without complications (Billakanty et al, 2008; Loh et al, 2013; Rubinshtein et al, 2001). We describe 14 patients with orthostatic intolerance (OI) post bariatric surgery. We report on OI (postural dizziness, palpitations and fainting), the results of cardiovascular autonomic testing and the associated and/or causative findings as well as reviewing the literature to consider the possible mechanisms.
\end{abstract}

We propose that the incidence of OI post-bariatric surgery is higher than considered, that certain cohorts may be more susceptible to complications, and that further research is needed to identify the prevalence and, ideally anticipate occurrence. With the increasing prevalence of obesity and required clinical interventions, further understanding of the pathophysiological processes causing autonomic dysfunction after bariatric interventions will aid management, which may differ in those with an underlying disposition to autonomic involvement, such as diabetics, in whom such procedures are increasingly used.

\title{
Keywords:
}

Bariatric surgery

$>$ Obesity

$>$ Autonomic

$>$ Orthostatic intolerance

$>$ Postural Tachycardia Syndrome

$>$ Syncope 


\section{Introduction}

Obesity is the fifth leading risk for death worldwide and is a predisposing factor for common related disorders, such as diabetes, hypertension, stroke, cancer and osteoarthritis (Wang et al, 2011). The healthcare footprint of these obesity related diseases indicate that the lifetime medical cost of treating an obese individual is $30 \%$ more than that of an individual of normal weight. It is estimated that obesity or obesity-related treatment accounts for up to $2.8 \%$ of a country's total healthcare expenditure (Withrow et al, 2011).

Obesity has reached epidemic proportions in many nations. In England, 61.3\% of the adult population is overweight (Dept of health, UK., 2013). The World Health Organisation (WHO) provides evidence that obesity worldwide has more than doubled since 1980 (WHO, Obesity \& overweight, 2013), with the United States of America (USA) and the United Kingdom (UK), amongst countries with the largest number of current and projected overweight and obese individuals (OECD, Key facts , 2010).

Figure 1: Past and projected overweight rates

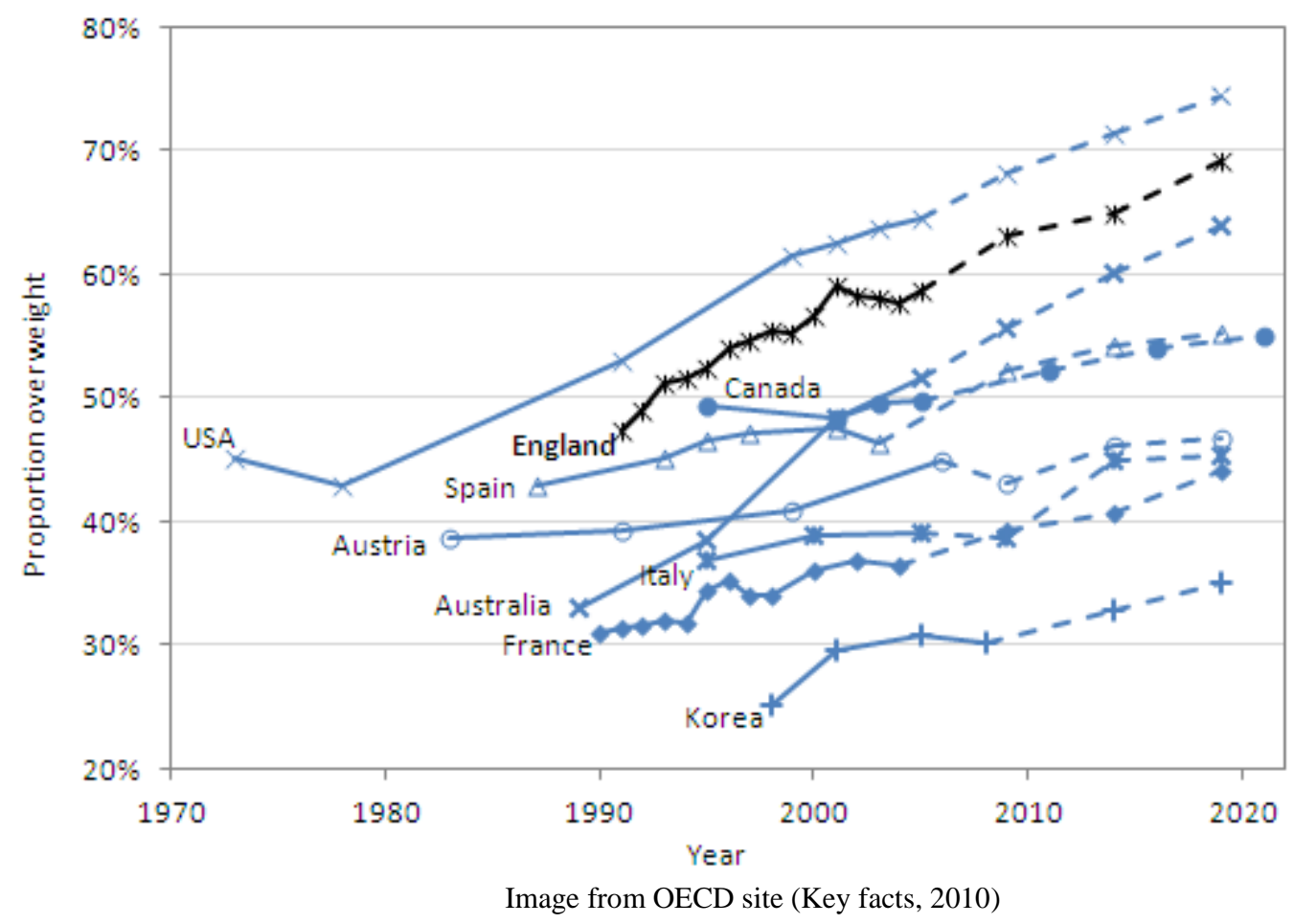


Bariatric medicine aims to treat obesity by utilising various approaches, such as specific weight loss or calorie controlled diets with or without exercise programmes, weight loss drugs (for example, Orlistat), and government drives, such as Britain's 'Change for Life'campaign and the '5 A Day Plan' (Dept of health, UK, 2013). Many bariatric patients have tried non-surgical weight loss programmes prior to considering surgery often with unsatisfactory results. Research has shown that dietary therapy can be effective, but not for sustained weight loss (Buchwald et al, 2004; Khwaja et al, 2010), as is also the case for pharmaceutical weight loss measures.

Bariatric surgery is considered to be one of the most effective methods to treat obesity, particularly morbid obesity. Its use in the treatment of Type 2 diabetes has been proposed, as it may be more cost effective than other treatments (Keidar, 2011). There are a number of procedures that can be used to adapt the gastrointestinal tract to reduce its volume and/or absorptive capacity (Khwaja et al, 2010). The procedure chosen for each surgery is patient specific with consideration of age, body-mass index (BMI), co-morbidities and previous medical history, amongst other aspects. The benefit of these procedures has been welldocumented and include the reduction of diabetic drugs (Schauer et al, 2012) and even improvement of autonomic function (Maser et al, 2007). After bariatric surgery patients are more productive, take less sick-leave, and utilise fewer healthcare resources. The long-term savings of bariatric surgery are estimated to offset the initial costs of the procedure in 2 to 4 years (Cremieux et al, 2008). These outcomes are beneficial to the patients' quality of life (QoL) (Sjostrom et al, 2007), as well as to the health service.

Documented side-effects, generally surgical in nature, present fairly soon post-operatively and are treated rapidly (Khwaja et al, 2010). As bariatric surgery gains popularity in the treatment of obesity, complications continue to emerge. We report on a series of such patients studied in our units who were referred because of orthostatic intolerance (OI) that may have had an autonomic aetiology. 


\section{Subjects and Methods}

\section{Patients:}

We evaluated the records of 14 patients referred over a 5 year period for exclusion of an underlying autonomic condition causing or contributing to OI after bariatric surgery (see Table 1). These symptoms included dizziness, palpitations and fainting (syncope) when upright. Some had additional symptoms affecting other systems, including gastrointestinal (GI) disturbances such as abdominal bloating, abdominal pain and diarrhoea.

Table 1: Presenting symptoms

\begin{tabular}{|c|c|c|c|c|c|c|}
\hline \multirow[b]{2}{*}{ Age } & \multirow[b]{2}{*}{$\begin{array}{l}\text { Time to } \\
\text { onset }\end{array}$} & \multicolumn{5}{|c|}{ Presenting Symptoms } \\
\hline & & Dizziness & Palpitations & $\begin{array}{c}\text { Gastric } \\
\text { symptoms }\end{array}$ & Faint/Falls & Sweating \\
\hline 23 & Unknown & + & - & + & - & - \\
\hline 25 & $\sim 5 \mathrm{mths}$ & + & + & + & - & + \\
\hline 31 & Unknown & - & - & + & - & - \\
\hline 36 & 12 mths & - & - & - & + & - \\
\hline 41 & 36 mths & - & - & + & - & - \\
\hline 43 & Post op & + & + & + & + & + \\
\hline 44 & $12 \mathrm{mths}$ & - & - & - & + & - \\
\hline 45 & Post op & + & - & + & + & - \\
\hline 45 & Post op & + & - & - & + & - \\
\hline 46 & Unknown & - & - & - & - & + \\
\hline 47 & Unknown & + & + & + & - & + \\
\hline 49 & 9 mths & - & - & + & - & + \\
\hline 52 & Post op & - & + & + & - & - \\
\hline 61 & $6 \mathrm{mths}$ & + & - & - & + & - \\
\hline
\end{tabular}

There were 12 females and 2 males, aged 23-61 (mean age: $42 \pm 9.9 y r s$ ). At initial clinical evaluation, some patients had pre-existing medical conditions that could be associated with impairment of the autonomic nervous system such as diabetes (see Table 2). $57.1 \%$ (8) patients had features of joint hypermobility/laxity (JHS), 62.5\% (5) of these with a confirmed diagnosis of Ehlers-Danlos III (EDS III) (see Table 2). There is a strong association, recently recognised, between JHS/EDS III and the postural tachycardia syndrome (PoTS) (Mathias et $a l, 2012)$. 
Table 2: Details of procedure, weight loss and allied features

\begin{tabular}{|c|c|c|c|c|}
\hline Age & Procedure & $\begin{array}{l}\text { Weight Loss } \\
\text { (kg) }\end{array}$ & $\begin{array}{c}\text { Features of JHS/ } \\
\text { EDS III }\end{array}$ & Relevant history \\
\hline 23 & Unknown & 47.6 & EDS III & Hypothyroidism \\
\hline 25 & Roux-en-Y & 40 & EDS III & $\begin{array}{l}\text { PCOS, Chronic Pain } \\
\text { Syndrome }\end{array}$ \\
\hline 31 & Roux-en-Y & Unknown & Hypermobility & Gastroparesis \\
\hline 36 & Roux-en-Y & 50 & JHS & Unknown \\
\hline 41 & LGB & 30 & JHS & CFS \\
\hline 43 & Roux-en-Y & 65 & EDS III & Hypertension \\
\hline 44 & Gastric Band & Unknown & Unknown & Unknown \\
\hline 45 & Roux-en-Y & 25.4 & Unknown & $\begin{array}{l}\text { Chronic Pain, } \\
\text { Dumping syndrome, } \\
\text { Small fibre neuropathy }\end{array}$ \\
\hline 45 & LSG & $\sim 27$ & Unknown & $\begin{array}{c}\text { Previously } \\
\text { hypertensive, Diabetic }\end{array}$ \\
\hline 46 & Roux-en-Y & Unknown & Unknown & $\begin{array}{l}\text { Rheumatoid arthritis, } \\
\text { PE }\end{array}$ \\
\hline 47 & Roux-en-Y & 57.2 & EDS III & CFS \\
\hline 49 & Roux-en-Y & $\sim 42.2$ & Unknown & $\begin{array}{l}\text { Ischaemic heart } \\
\text { disease, Eating } \\
\text { disorder }\end{array}$ \\
\hline 52 & Unknown & 25.4 & EDS III & CFS \\
\hline 61 & LSG & $\sim 40$ & Unknown & Unknown \\
\hline
\end{tabular}

Note: LSG - Laparoscopy Sleeve Gastrectomy; LGB - Laparoscopy Gastric Band;

CFS - Chronic Fatigue Syndrome; PE - Pulmonary Embolism; PCOS - Polycystic Ovarian Syndrome

Autonomic investigations were conducted to assess cardiovascular function to exclude possible autonomic disease or dysfunction. All tests were performed using protocols established in our centres (Mathias et al, 2013).

Autonomic Function Screening Testing, included head up tilt to $60^{\circ}$ and cardiovascular autonomic responses to various pressor (e.g. isometric exercise, cutaneous cold \& mental arithmetic) and respiratory stimuli (e.g. respiratory sinus arrhythmia, Valsalva manoeuvre \& hyperventilation) designed to assess the sympathetic and parasympathetic function.

Blood for plasma catecholamines (noradrenaline, adrenaline and dopamine) levels were taken while supine and after 10 minutes of tilt or after 5 minutes of standing

Prolonged head up tilting was performed if needed. 
$>$ Food challenge (liquid meal challenge) (Mathias et al, 2013) was used to identify abnormal BP and/or HR changes in response to ingestion of food; and to HUT pre and 45 minutes post ingestion of food.

$>24$ hour ambulatory BP and HR monitoring using the Autonomic Protocol included the responses in different positions to evaluate the effects of posture, exercise and food stimuli encountered in daily life (Stuebner et al, 2013).

> An atropine test (Mathias et al, 2013) was performed only in patients who had autonomic mediated syncope (AMS), with both a vasodepressor and cardio-inhibitory component, to separate the two components.

\section{Results}

\section{Autonomic Function Testing}

These tests were performed on all 14 patients. Responses to pressor tests (see methods section) were present in all. None of the results indicated cardiovascular autonomic failure. A syncopal event was provoked in $7.1 \%$ (1) patients during AFT with a HR fall of $<40 \mathrm{~b} / \mathrm{m}$ necessitating an Atropine test (see below). $35.7 \%$ (5) of the patients had a HR increase with orthostasis meeting the criteria for the PoTS. 50\% (7) had low levels of BP $(<110 \mathrm{mmHg})$ during this test.

\section{Plasma Catecholamines}

$42.9 \%$ (6) patients had blood samples taken whilst supine and during orthostasis. The plasma catecholamine levels were all within the normal range of our laboratory (normal range for noradrenaline: 200-500 pg/ml; adrenaline: 20-150 pg/ml; dopamine: 10-80 pg/ml).

\section{Prolonged Tilt Test}

This test was performed on 50\% (7) patients when the shorter period of tilt did not result in cardiovascular autonomic changes. An excessive HR response of $>30 \mathrm{~b} / \mathrm{m}$ with symptoms was observed in $42.9 \%$ (2) patients during head up tilt, again meeting the diagnostic criteria for the PoTS $(17,21) .14 .3 \%$ ( 1) patients experienced a syncopal episode, with the lowest $\mathrm{HR}$ recorded at $<40 \mathrm{~b} / \mathrm{m}$ requiring an atropine test (see below).

\section{$\underline{\text { Meal Test }}$}


$57.1 \%$ (8) patients underwent liquid meal challenge as some were referred because of postprandial symptoms of nausea, diarrhoea, bloating, abdominal pain and two referrals specifically queried the dumping syndrome. In $37.5 \%$ ( 3) patients there were HR rises of $>30 \mathrm{~b} / \mathrm{m}$ during post-meal tilt associated with symptoms (see Table 3), meeting the diagnostic criteria for PoTS (17).

\section{4 hour Ambulatory BP \& HR monitoring with Autonomic Protocol}

Low levels of daytime BP (90 -110 mm Hg of systolic BP) were present in $23.1 \%$ (3) patients. One patient did not wish to complete this test. The nocturnal circadian fall in BP was present $46.2 \%$ (6) of patients; a modest fall was noted in $23.1 \%$ (3); the fall was absent in $7.7 \%$ (1) (this patient did not sleep well during monitoring); and was reversed in $15.4 \%$ (2), (both having not slept well). A high daytime average HR in $23.1 \%$ (3) of patients was noted (87-94 b/m). Evidence for PoTS during recording was observed in $15.4 \%$ (2) of patients.

\section{Atropine Test}

The antimuscarinic agent, atropine, was used to increase HR during HUT to determine if a provoked syncopal event was predominantly vasodepressor or cardio inhibitory in nature. The test was performed on 2 patients who experienced syncopal episodes on tilt, during which HR fell lower than $40 \mathrm{~b} / \mathrm{m}$ in addition to a fall in BP. In each patient the syncopal episodes were characteristic of the vasodepressor form of autonomic mediated syncope (AMS), and there was therefore no case for consideration of a cardiac demand pacemaker.

Table 3: Key cardiovascular autonomic features on testing

\begin{tabular}{|c|c|c|c|}
\hline \multirow{2}{*}{ Age } & \multicolumn{3}{|c|}{ Data obtained from tests } \\
& Low BP & Pre Syncope symptoms & PoTS \\
\hline 23 & + & /Syncope & + \\
\hline 25 & - & - & - \\
\hline 31 & - & - & - \\
\hline 36 & + & + & + \\
\hline 41 & + & - & - \\
\hline 43 & - & + & + \\
\hline 44 & + & - & - \\
\hline 45 & - & + & - \\
\hline 45 & + & - & - \\
\hline 46 & - & + & - \\
\hline 47 & + & - & + \\
\hline
\end{tabular}




\begin{tabular}{|l|l|l|l|}
\hline 49 & + & - & - \\
\hline 52 & + & + & + \\
\hline 61 & - & + & - \\
\hline
\end{tabular}

\section{Discussion:}

In this study, we have retrospectively reviewed the causes and autonomic investigations for OI in patients referred because of apparent OI that occurred post-bariatric surgery, and to exclude an autonomic disorder. The symptom onset varied from immediately post-operative to 3 years post-surgery.

Detailed autonomic function testing for causes of intermittent or irreversible autonomic failure (AF) indicated that there was no evidence for impairment of the sympathetic vasoconstrictor function or cardiac parasympathetic function, thus excluding AF. 57.1\% (6) of the cohort had low supine levels of BP (systolic readings of $<110 \mathrm{mmHg}$ ) during testing. $42.9 \%$ (6) of patients reported pre-syncopal symptoms and $14.3 \%$ (2) patients experienced syncopal episodes during HUT, pHUT and/or standing. 35.7\% (5) had an inappropriate HR response to orthostasis with increases of up to $59 \mathrm{~b} / \mathrm{m}$. In these patients, the criteria for PoTS was fulfilled, with a rise in HR of $30 \mathrm{~b} / \mathrm{m}$ or more, or a HR of $>120 \mathrm{~b} / \mathrm{m}$ with orthostasis either during a 10 minute tilt or standing (Mathias et al, 2012; Freeman et al, 2011). Each of these patients also had features of the Joint Hypermobility Syndrome (JHS) with a later confirmed diagnosis of Ehlers-Danlos Syndrome hypermobility type III (EDS III) which is strongly associated with PoTS (Mathias et al, 2012). All of these patients also underwent the Roux-enY gastric bypass surgery.

We have reviewed previous publications, mainly case reports, on OI and Autonomic dysfunction after bariatric surgery, and these are referred to below.

In 2001 Rubinshtein et al reported a single patient with severe orthostatic hypotension $(\mathrm{OH})$ after substantial weight loss post-bariatric surgery. $\mathrm{OH}$ was only resolved after weight gain. Autonomic testing was not performed and whether $\mathrm{OH}$ was a transient autonomic disturbance, spontaneously resolved or was rectified by medication remains unclear. An explanation is that as weight increased so did BP (Billakanty et al,2008; Rubinshtein et al, 2001). The reverse, BP decrease with weight loss, is consistent with observations in 
hypertensive patients treated with antihypertensive agents and also in hypertensive patients who underwent bariatric surgery and lost weight (Schauer et al, 2012; Maser et al, 2007).

A series similar in number to ours was reported in 2008 by Billakanty et al on OI after bariatric surgery. All patients underwent tilt table testing although without autonomic investigation. Of the 15 patients reported 53\% (8) had a neurocardiogenic response, 20\% (3) had a dysautonomic response and 20\% (3) had tachycardia and a PoTS response. In their study, Isoproterenol was infused, a drug known to induce syncope even in those without a history of syncope, and whether this contributed to tachycardia, independently of the underlying pathophysiological processes remains unclear. Of note is that prior to tilt testing, 3 patients had pacemakers fitted (with no benefit), 12 had been evaluated by a neurologist (without autonomic testing), 9 by an endocrinologist, and 5 by an ENT specialist, emphasising the problems when an autonomic cause is initially not considered. This study concluded that further investigation was necessary to determine the true incidence of OI following bariatric surgery, to identify patients at greater risk for developing OI following this surgery and to improve understanding of the underlying pathophysiology.

Recently, Loh et al described a patient with persistent bradycardia post-surgery $(\sim 40 \mathrm{~b} / \mathrm{m})$ who had a neurocardiogenic form of syncope on tilt table testing. The description indicates that at the beginning of tilt, the HR rose to $120-130 \mathrm{~b} / \mathrm{m}$, despite a resting $\mathrm{HR}$ of $40 \mathrm{~b} / \mathrm{m}$ and consistent with a diagnosis of PoTS. Consequently a pacemaker was fitted with apparent resolution of symptoms. The length of follow up with this patient was not described. As in previous studies, autonomic function testing was not carried out.

Due to the strong association between JHS/EDS III and PoTS (Mathias et al, 2012; Fikree et $a l, 2013)$, it should be important to consider this electively in anticipation of possible sideeffects of surgery. JHS/EDS III can be clinically determined readily (Fikree et al, 2013) and is of especially importance in those undergoing surgery as this connective tissue disorder is associated with GI dysfunction (Fikree et al, 2013) and also influences response to anaesthesia, to analgesics post-operatively and to recovery/wound healing time (Fikree et al, 2013).

This retrospective study has limitations as referrals were made by healthcare practitioners who were aware of our autonomic interests and considered autonomic dysfunction as a 
possibility. There are likely, as from the literature analysed, to be many more patients with OI in whom an autonomic aetiology is not considered. The size of the cohort is small, drug regimens and procedures performed varied between patients and also the time of evaluation from surgery. It would have been ideal to have tested autonomic function pre surgery.

We have speculated on some of the mechanisms, including gut peptides that may contribute to OI after bariatric surgery.

Weight loss itself may be the factor in some, especially if substantial. The largest proportion of weight appears to be lost 6 to 24 months post-surgery (Brolin et al, 1994; Behbehrani et al, 2014). The physiological changes from reducing BMI from severely obese to normal may be comparable to those with anorexia, in whom autonomic impairment, affecting sympathetic function, has been well documented (Cong et al, 2004). Repeated hypoglycaemia (Cryer, 2005), which may occur post-bariatric surgery, may contribute. Plasma catecholamine levels, a marker of sympathetic activation, are lower in anorexic patients than controls (Cong et al, 2004); there have been no similar studies post-bariatric surgery. Grassi et al (2014) has reported that elevated sympathetic nerve activity (SNA) in the obese is markedly reduced with weight loss post-bariatric surgery.

Gut peptides have a role in cardiovascular autonomic regulation, as exemplified in studies in various autonomic disorders (Bishop et al, 2013). Levels of gut peptides are altered postbariatric surgery, generally speeding up the feeling of satiety due to increases in peptide YY (PYY) (Vincent et al, 2008; Da Silva et al, 2012), PYY binds to neuropeptide Y (NPY), which is responsible for increasing food intake, thereby negating its function. This raises the question of whether changes in gut peptides and/or hormones impact other circulating centrally mediated hormones have the dual purpose of aiding gut function and control of BP and HR levels e.g., NPY, acetylcholine, and noradrenaline (Bishop et al, 2013).

There is increasing evidence that leptin not only triggers satiety but may be involved in autonomic regulation (Paolisso et al, 2000). Leptin may have vasodilator effects (Lembo et $a l, 2000)$. As the stomach size is reduced in these patients, the release of leptin to signal satiety could be triggered earlier. Combined with the likely need for frequent smaller meals, there could be a more frequent release of leptin which as a vasodilator, could explain the lowering in $\mathrm{BP}$ and/or OI. The role of leptin in autonomic regulation, however, remains 
controversial. Some report vasoconstrictor effects (Geloneze et al, 2001). Leptin levels decrease as the BMI decreases post-surgery (Ram et al, 2005, Takimoto et al, 2014) also noted in anorexic patients (Machleidt et al, 2013). Leptin infusion increases vasoconstrictor SNA measured by sympathetic microneurography (Cammisotto et al, 2007), and the decrease in leptin levels with surgical weight loss (Servalle et al, 2014) may contribute through a decrease in sympathetic activity. Leptin may also be further reduced by the loss of leptinreleasing white adipose tissue (Nayaga et al, 2001) post-surgery, which could worsen OI. The exact function of leptin requires further investigation as does another vasodilator peptide, Ghrelin (Lembo et al, 2000).

Infusion of ghrelin decreases BP without compensatory increases in HR, suggesting effects independent of vasodilatation alone (Nayaga et al, 2001). It is relevant that 54\% of our case series were found to have features of JHS/EDS III (57.1\% with a confirmed diagnosis of EDS III), compared to the prevalence of $20 \%$ in the general population (Mulvey et al, 2013), potentially predisposing them to be sensitised to the apparent depressor effects of ghrelin. Rodent studies have provided evidence of ghrelin's neuroactive properties, particularly on autonomic centres (e.g., nucleus of the solitary tract, dorsomotor nucleus of the vagus), potentially influencing BP regulation and parasympathetic cardiac tone respectably, both primary symptoms of OI. Ghrelin levels increase and leptin levels decrease during food deprivation (Saladin et al, 1995), which may be comparable to the marked reduction in calorific intake post-surgery. With potentially increased circulatory levels of ghrelin postbariatric surgery, it could be argued that ghrelin's peripheral vasodilatory affects and central anti-sympathetic affects may have contributed to the OI.

A recent study (Lee et al, 2015) looking at the prevalence of hypoglycaemic symptoms in patients after bariatric surgery found that autonomic symptoms were more prevalent than neuroglycopenic symptoms. However, some symptoms of hypoglycaemia overlap autonomic symptoms and hypoglycaemia may, in fact, bring on autonomic symptoms. It is unclear from this questionnaire study if patients reporting these symptoms had clinically confirmed hypoglycaemia and/or had experienced hypoglycaemic and autonomic symptoms independent of each other. They also concluded though that the prevalence of these symptoms are under-reported. 
There thus are several mechanisms by which the intricate homeostasis of energy balance and autonomic regulation may be disturbed post-bariatric surgery. We believe that increasing use and success of bariatric surgery for obesity provides a compelling need to investigate and elicit the mechanism of the disturbance of the OI, be they autonomic, hormonal or a combination, so it can be remedied.

\section{Conclusions:}

With rising global obesity rates and increasing use of bariatric surgery, our series, along with other reports, indicate that autonomic dysfunction causing OI occurs after bariatric surgery. These findings, in particular with the 2008 series, indicate that OI is likely to be underreported, even if recognised. A retrospective survey in bariatric centres is needed to determine the prevalence of OI after bariatric surgery. This should be in concert with a prospective study, ideally including a pre-operative assessment to exclude initial OI, with a focus on key factors, associated disorders and if possible mechanisms that may predispose or contribute to OI after bariatric intervention. 
Acknowledgements:

We would like to thank Dr E. Vichayanrat, Mrs M. K .Tippetts \& Mr M. Peche for their invaluable guidance and support. 


\section{References:}

1. Behbehani, F., Ammori, B. J., New, J. P., Summers, L. K. M., Soran. H. \& Syed, A. A. (2014). 'Metabolic outcomes 2 years following gastric bypass surgery in people with type 2 diabetes: an observational cohort study'.QJM: An international journal of Medicine.107 (9), 721-726.

2. Billakanty, S. R., Kligman, M. D., Kanjwal, Y. M., Kosinski, D. J., Maly, T. G., Karabin, B. and Grubb, B. P. (2008). New Onset Orthostatic Intolerance Following Bariatric Surgery. PACE. 31, 884-888.

3. Bishop, A. E. \& Polak, J. M. (2013). 'The Gut and the Autonomic Nervous System' in Autonomic Failure, A textbook of Clinical disorders of the Autonomic Nervous System, $5^{\text {th }}$ Edn, ed. C. J. Mathias (Oxford: Oxford University Press), 194-204.

4. Brolin, R. E., Robertson, L. B., Kenler, H. A. \& Cody. R. P. (1994). 'Weight Loss and Dietary Intake after Vertical Banded Gastroplasty and Roux-en-Y Gastric Bypass'. Annals of Surgery. 220 (6), 782-790. 
5. Buchwald, H., Avidor, Y., Braunwald, E., Jensen, M. D., Pories, W., Fahrbach, K. \&Schoelles, K. (2004). Bariatric Surgery- A Systematic Review and Meta-analysis. JAMA. 292, 1724-1737.

6. Cammisotto, P. G. \& Bendayan, M. (2007). 'Leptin secretion by white adipose tissue and gastric musoca'. Histol Histopathol. 22, 199-210.

7. Cong, N. D., Saikawa, T., Ogawa, R., Hara, M., Takahashi, N., \& Sakata, T. (2004). 'Reduced 24 hour ambulatory blood pressure and abnormal heart rate variability in patients with dysorexia nervosa'. Heart. 90, 563-564.

8. Cremieux, P., Buchwald, H., Shikora, S. A., Ghosh, A., Yang, H. E. \&Buessing, M. (2008). A Study on the Economic Impact of Bariatric Surgery. Am J Manag Care. 14(9), 589-596.

9. Cryer, P. E. (2005). 'Mechanisms of hypoglycaemia-associated autonomic failure and its components syndromes in diabetes. Diabetes. 54, 3592-3601.

10. Da Silva, A. \& Bloom, S. R. (2012). 'Gut Hormones and Appetite Control: A Focus on PYY and GLP-1 as Therapeutic Targets in Obesity. Gut and Liver. 6 (1), 10-20.

11. Department of health (UK). Reducing obesity and improving. England. March 2013.http://www.dh.gov.uk/health/2012/04/obesityfacts/ (accessed 23 Sept 2013). 
12. Department of health (UK). Reducing obesity and improving. England. March 2013. http://www.nhs.uk/Change4Life/Pages/change-for-life.aspx (accessed 23 Sept 2013).

13. Fikree, A., Aziz, Q. and Grahame, R. (2013). Joint Hypermobility Syndrome. Rheu.Dis.Clin. North Am. 39(2), 419-430.

14. Freeman, R., Wieling, W., Axelrod, F. B., Benditt, D. G., Benarroch, E., Biaggioni, I., Cheshire, W. P., Chelimsky, T., Cortelli, P., Gibbons, C. H., Goldstein, D. S., Hainsworth, R., Hilz, M., Jacob, G., Kaufmann, H., Jordan, J., Lipsitz, L. A., Levine, B. A., Low, P. A., Mathias, C. J., Raj, S. R., Robertson, D., Sandroni, P., Schatz, P., Schondorff, R., Stewart, J. M. and van Dijk, J. G. (2011). Consensus statement on the definition of orthostatic hypotension, neurally mediated syncope and the postural tachycardia syndrome. ClinAuton Res. 21, 69-72.

15. Geloneze, B., Tambascia, M. A., Pareja, J. C., Repetto, E. M., Magna, L. A., \& Pereira, S. G. (2001). 'Serum Leptin Levels After Bariatric Surgery Across a Range of Glucose Tolerance from Normal to Diabetes'. Obesity Surgery. 11, 693-698.

16. Keidar, A. (2011). 'Bariatric Surgery for Type 2 Diabetes Reversal: The Risks'. Diabetes Care. 34 (2), 361-366.

17. Khwaja, H. A. \&Bonanomi, G. (2010) Batriatric surgery: techniques, outcomes and complications. Current Anaesthesia \& Critical Care. 21, 31-38. 
18. Lee, C. J., Clark, M. J., Schweitzer, M., Magnuson, T., Steele, K., Koerner, O. \& Brown, T.T. (2015). 'Prevalence of and Risk Factors for Hypoglycemic Symptoms After Gastric Bypass and Sleeve Gastrectomy’. Obesity. 23 (5), 1079-1084.

19. Lembo, G., Vecchione. C., Fratta, L., Marino, G., Trimarco, V., d'Amati, G. et al. (2000). 'Letpin induces direct vasodilation through distinct endothelial mechanisms. Diabetes. 49, 293-297.

20. Loh, K. P. and Ogunneye, O. (2013). Malignant cardioinhibitory vasovagal syncopeAn uncommon cardiovascular complication of Roux-en-Y gastric bypass surgery: The fainting syndrome! International Journal of Cardiology.164, 38-39.

21. Machleidt, F., Simon, P., Krapalis, A. F., Hallschmid, M., Lehnert, H. \& Sayk, F. (2013). 'Experimental hyperleptinemia acutely increases vasoconstrictory sympathetic nerve activity in healthy humans'.J Clin Endrocrinol Metab. 98, 491496.

22. Maser, R. E., Lenhard, M. J., Irgau, I. \& Wynn, G. M. (2007). Impact of Surgically Induced Weight Loss on Cardiovascular Autonomic Function: One-Year Follow-up. Obesity. 15, 364-369.

23. Mathias, C. J., Low, D. A., Iodice, V., Owens, A. P., Kirbis, M. and Grahame, R. (2012). Postural tachycardia syndrome - current experience and concepts. Nat. Rev. Neurol.8, 22-34. 
24. Mathias, C.J., Low, D. A., Iodice, V., and Bannister, R. (2013). 'Investigation of autonomic disorders,' in Autonomic Failure, A textbook of Clinical disorders of the Autonomic Nervous System, $5^{\text {th }}$ Edn, ed. C. J. Mathias (Oxford: Oxford University Press), 259-289.

25. Mulvey, M. R., Macfarlane, G.J., Beasley, M., Symmons, D. P., Lovell, K., Keeley, P., Woby, S. \& McBeth, J. (2013). Modest association of joint hypermobility with disabling and limiting musculoskeletal pain: results from a large-scale general population-based survey. Arthritis care \& research.65,1325-1333.

26. Nagaya, N., Kojima, M., Uematsu. M., Yamagishi, M., Hosoda, H., Oya, H., Hayashi, Y. \&Kangawa, K. (2001). Hemodynamic and hormonal effects of human ghrelin in healthy volunteers. American journal of physiology Regulatory, integrative and comparative physiology.280, R1483-1487.

27. Organisation for Economic Co-operation and Development. Obesity and the Economics of Prevention: Fit not Fat -United Kingdom (England) Key Facts. Sept 2010.http://www.oecd.org/health/healthsystems/obesityandtheeconomicsofpreventionfitnotfatunitedkingdomenglandkeyfacts.htm (accessed 23 Sept 2013).

28. Paolisso, G., Manzella, D., Montano, N., Gambardella, A., and Varrichio, M. (2000). 'Plasma Leptin Concentrations and Cardiac Autonomic Nervous System in Healthy 
Subjects with Different Body Weights. The Journal of Clinical Endocrinology \& Metabolism. 85(5), 1810-1814.

29. Ram, E., Vishne, T., Maayan, R., Lerner, I., Weizman, A., Dreznik, Z., Konstantin, B., Seror, D., \& Pnina, V. (2005). 'The relationship between BMI, Plasma leptin, Insulin and ProInsulin before and after Laparoscopic Adjustable Gastric Banding'. Obesity Surgery. 15, 1456-1462.

30. Rubinshtein, R., Elad, H. and Bitterman, H. (2001). Severe Orthostatic Hypotension Following Weight Reduction Surgery. Arch Intern Med. 161, 2145-2147.

31. Saladin, R., De Vos, P., Guerre-Millo, M., Leturque, A., Girard, J., Staels, B.\& Auwerx, J. (1995). Transient increase in obese gene expression after food intake or insulin administration. Nature 377, 527-529.

32. Schauer, P. R., Sangeeta, R., Kashyap., Wolski, K., Brethauer, S. A., Kirwan, J. P., Pothier, M. P. H., Thomas, S., Abood, B., Niessen, S. E., Bhatt, D. L. (2012). Bariatric Surgery versus Intensive Medical Therapy in Obese Patients with Diabetes. N Engl J Med. 366, 1567-1576.

33. Servalle, G., Colombo, M., Perego, P., Giardini, V., Volpe, M., Dell’Oro, R., Mancia, G. \& Grassi, G. (2014). 'Long Term Sympathoinhibitory Effects of Surgically Induced Weight Loss in Severe Obese Patients'. Hypertension. 64, 431-437. 
34. Sjostrom, L., Narbro, K., Sjostrom, D., Karason, K., Larsson, B., Wedel, H., Lystig, T., Sullivan, M., Bouchard, C., Carlsson, B., Bengtsson, C., Dahlgren, S., Gummesson, A., Jacobson, P., Karlsson, J., Lindroos, A., Lonroth, H., Naslund, I., Olbers, T., Stenlof, K., Torgerson, J., Agren, G., Carlsson, L. (2007). Effects of Bariatric Surgery on Mortality in Swedish Obese Subjects. NEJM.357 (8), 741-752.

35. Stuebner, E., Vichayanrat, E., Low, D. A., Mathias, C. J., Isenmann, S. and Haensch, C. (2013). Twenty-four hour non-invasive ambulatory blood pressure and heart rate monitoring in Parkinson's Disease. Frontiers in Neurology. 4, 1-14.

36. Takimoto, Y., Yoshiuchi, K., Ishizawa, T., Yamamoto, Y., \& Akabayashi, A. (2014). 'Autonomic dysfunction responses to head up tilt in anorexia nervosa'. Clinical Autonomic Research. 24, 175-181.

37. Vincent, R. P. \&Le Roux, C. W. (2008). Changes in Gut Hormones After Bariatric Surgery.Clinical Endocrinology. 69, 173-179.

38. Wang, C.Y., McPherson, K., Marsh, T., Gortmaker, S. L. \& Brown, M. (2011).Health and economic burden of the projected obesity trends in the USA and the UK. Lancet. $378,815-825$.

39. Withrow, D. \& Alter, D. A. (2011). The Economic burden of obesity worldwide:a systemic review of the direct costs of obesity. Obes. Rev.12, 131-141. 
40. World Health Organisation. Obesity and overweight - Factsheet $\mathrm{N}^{0} 311$. March 2013. http://www.who.int/mediacentre/factsheets/fs311/en/ (accessed 23 Sept 2013). 